MMP3, SPINT2, GREM1, MATN3, ADAMTS4). The PCA analysis revealed that the experimental treatment (PC1, Fig $1 \mathrm{~A}$ ) accounted for $61 \%$ variability in the expression of these genes, while $19 \%$ was attributed to interdonor variability (PC2). Dm-aKG diminished TGF $\beta$-induced production of aSMA protein (72h, $p=0.02$, mean O.D. \pm SD in TGF $\beta+d m$ - $\alpha$ KG vs. TGF $\beta: 0.34$ \pm 0.38 vs. $3.1 \pm 2.3$ ) and repressed TGF $\beta$-driven secretion of fibronectin protein (72h, $p=0.047,0.5 \pm 0.1$ vs. $1.2 \pm 0.6)$. Dm- $a K G$ reduced the contractile capacity of TGF $\beta$-stimulated DF in collagen gel contraction assay $(p=0.003,0$ vs. $67.1 \pm 5.4 \%)$. Additionally, dm-aKG decreased TGF $\beta$-driven production of IL- 6 transcripts $(24 \mathrm{~h}, \mathrm{p}=0.05,2.9 \pm 0.6$ vs $1.9 \pm 0.3)$ and protein (24h, p=0.0005, $5.9 \pm 1.2$ vs $3 \pm 0.7$, Fig $1 B)$, but did not increase the apoptosis of DF (24h, $48 \mathrm{~h}, 72 \mathrm{~h})$
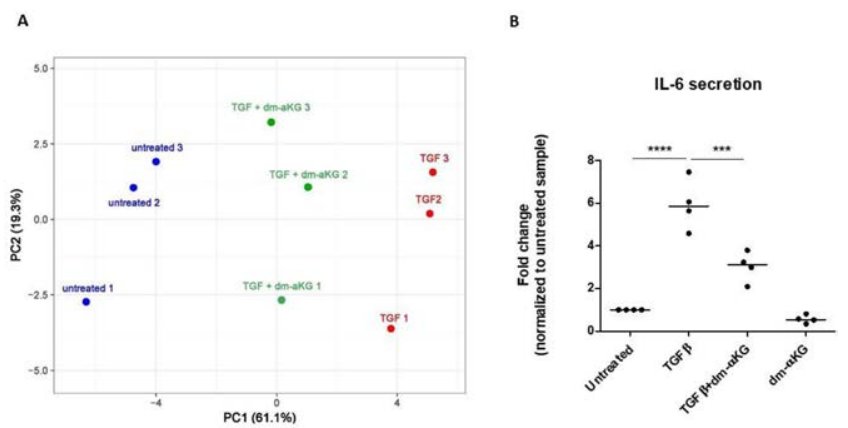

Fig 1. A Supervised PCA analysis of RNA-seq data. B. IL-6 secretion (ELISA).

Conclusion: Dm-aKG counteracted TGF $\beta$-induced myofibroblast differentiation by regulating the cytoskeleton organization and ECM dynamics in DF and blocked the TGF $\beta$-induced IL-6 production. This closely links metabolism to inflammatory and pro-fibrotic responses in DF. Therefore, regulating intracellular aKG might offer a novel strategy in combating the inflammatory and fibrotic stages of skin fibrosis in SSc.

Acknowledgments: This work was supported by a research grant from FOREUM Foundation for Research in Rheumatology.

Disclosure of Interests: Blaž Burja: None declared, Gabriela Kania: None declared, Matija Tomsic: None declared, Snežna Sodin-Šemrl: None declared, Oliver Distler Grant/research support from: Grants/Research support from Actelion, Bayer, Boehringer Ingelheim, Competitive Drug Development International Ltd. and Mitsubishi Tanabe; he also holds the issued Patent on mir-29 for the treatment of systemic sclerosis (US8247389, EP2331143)., Consultant of: Consultancy fees from Actelion, Acceleron Pharma, AnaMar, Bayer, Baecon Discovery, Blade Therapeutics, Boehringer, CSL Behring, Catenion, ChemomAb, Curzion Pharmaceuticals, Ergonex, Galapagos NV, GSK, Glenmark Pharmaceuticals, Inventiva, Italfarmaco, iQvia, medac, Medscape, Mitsubishi Tanabe Pharma, MSD, Roche, Sanofi and UCB, Speakers bureau: Speaker fees from Actelion, Bayer, Boehringer Ingelheim, Medscape, Pfizer and Roche, Katja Lakota: None declared, Mojca Frank-Bertoncelj: None declared

DOI: 10.1136/annrheumdis-2020-eular.3677

\section{SAT0293 EXOSOMES DERIVED FROM PLASMA OF SYSTEMIC SCLEROSIS (SSC) PATIENTS AND FROM SSC CULTURED FIBROBLASTS CONTAIN PRO-FIBROTIC MIRNA SIGNATURES AND COULD INDUCE MYOFIBROBLAST DIFFERENTIATION IN VITRO}

C. Corallo ${ }^{1}$, M. Cutolo ${ }^{2}$, S. Soldano ${ }^{2}$, E. Selvi ${ }^{1}$, F. Bellisai ${ }^{1}$, N. Giordano ${ }^{1}$. ${ }^{1}$ University of Siena, Scleroderma Unit, Department of Medicine, Surgery and Neurosciences, Siena, Italy; ${ }^{2}$ IRCCS San Martino Polyclinic Hospital, University of Genoa, Rheumatology, Genoa, Italy

Background: Exosomes generated great resonance in the last few years due to their important roles in different biological pathways and diseases, including systemic sclerosis (SSc) (1). They are lipid-like nanovesicles containing biomarkers, such as proteins, lipids, macromolecules and nucleic acids, including microRNA (miRNA) (2). Exosomes are implicated in intercellular communication by fusing and releasing their cargo into the target cells (3).

Objectives: In the present study, we evaluated the potential of exosomes deriving from plasma of SSc patients or generating from cultured SSc fibroblasts to drive the fibrotic signaling in the disease.

Methods: Exosomes were isolated from plasma of $n=10$ SSc patients and from $n=10$ control subjects. Exosomes were also purified from cell culture supernatants of SSc fibroblasts and of control fibroblasts. Exosome size and concentration were assessed by Nanosight Particle Tracking Analysis (NTA) and by transmission electron microscopy (TEM). The content of anti-fibrotic (let-7a, 146a, 200a, 223a) and pro-fibrotic $(150,155)$ miRNAs was assessed in all the plasma-derived and cell culture-derived exosome populations by semiquantitative real time PCR. Finally, isolated exosomes were used to stimulate control dermal fibroblasts in culture. Gene expressions (COL1A1, ACTA2 and TAGLN) were assessed by quantitative real time PCR (qRT-PCR) and protein levels (type-I-collagen, $\alpha$-SMA and SM22) by immunofluorescence (IF).

Results: Exosomes isolated from SSc plasma samples showed higher concentration $\left(3.3 \times 10^{10} \pm 1.1 \times 10^{10}\right.$ particles $\left./ \mathrm{mL}\right)$ compared to those isolated from control plasma ones $\left(1.5 \times 10^{10} \pm 0.4 \times 10^{10}\right.$ particles $\left./ \mathrm{mL}\right)(\mathrm{p}<0.01)$. The exosome size did not differ between SSc and control plasma samples and ranged from $50 \mathrm{~nm}$ to $150 \mathrm{~nm}$. Similar results were obtained with exosomes generated from fibroblast cultures: the concentration was higher in SSc fibroblasts $\left(1.1 \times 10^{10} \pm 0.2 \times 10^{10}\right.$ particles $\left./ \mathrm{mL}\right)$ than in control ones $\left(0.4 \times 10^{10} \pm 0.1 \times 10^{10}\right.$ particles $/ \mathrm{mL})(p<0.05)$ with no significant differences in size distribution. The content of all anti-fibrotic (let-7a, 146a, 200a, 223a) miRNAs was decreased in exosomes coming from both SSc plasma samples and from SSc fibroblasts with respect to control plasma samples $(p<0.05)$ and to control fibroblasts $(p<0.05)$. On the contrary, the pro-fibrotic $(150,155)$ miRNAs were significantly upregulated in exosomes deriving from SSc plasma samples and from SSc fibroblasts, with respect to control plasma samples $(p<0.05)$ and to control fibroblasts $(p<0.05)$. Finally, only exosomes coming from SSc plasma samples or SSc fibroblast cultures were able to induce pro-fibrotic gene (COL1A1, ACTA2 and TAGLN) and protein (type-l-collagen, a-SMA and SM22) expression in control fibroblasts. No pro-fibrotic induction was seen in presence of exosomes isolated from control plasma samples or control fibroblast cultures.

Conclusion: This study demonstrates that plasma from SSc patients contains higher concentration of exosomes compared to plasma from control subjects and SSc-derived exosomes contain specific pro-fibrotic miRNA signatures that can induce myofibroblast differentiation in vitro. These results suggest that exosomes could be fibrotic drivers towards non-affected areas in vivo, and they might represent novel targets for precision medicine treatments in SSc.

References:

[1] Zhu T, Wang $Y$, Jin H, Li L. The role of exosome in autoimmune connective tissue disease. Ann Med. 2019 Mar;51(2):101-108.

[2] Wermuth PJ, Piera-Velazquez S, Rosenbloom J, et al. Existing and novel biomarkers for precision medicine in systemic sclerosis. Nat Rev Rheumatol. $2018 \mathrm{Jul} ; 14(7): 421-432$

[3] Colletti M, Galardi A, De Santis M, et al. Exosomes in Systemic Sclerosis: Messengers Between Immune, Vascular and Fibrotic Components? Int J Mol Sci. 2019 Sep 4;20(18). pii: E4337.

Disclosure of Interests: Claudio Corallo: None declared, Maurizio Cutolo Grant/ research support from: Bristol-Myers Squibb, Actelion, Celgene, Consultant of: Bristol-Myers Squibb, Speakers bureau: Sigma-Alpha, Stefano Soldano: None declared, Enrico Selvi: None declared, Francesca Bellisai: None declared, Nicola Giordano: None declared

DOI: 10.1136/annrheumdis-2020-eular.4848

SAT0294

\section{IL33 ACTIVATES FIBROBLASTS AND INDUCES SKIN} FIBROSIS IN SYSTEMIC SCLEROSIS

X. Wu ${ }^{1}$, B. Ming ${ }^{1}$, L. Dong ${ }^{1} .{ }^{1}$ Tongji Hospital, Tongji Medical College, Huazhong University of Science and Technology, Department of Rheumatology and Immunology, Wuhan, China

Background: Systemic sclerosis (SSc) is a chronic immune-mediated autoimmune disease that is characterized by fibrotic changes of the skin and interna organs, which in turn leads to distortion of tissue structure and gradual loss of organ function. So far, there is still no treatment allows full recovery from this severe disorder. Therefore, it is of great social significance to study the pathogenesis of this disease and find new targets for treatment. Interleukin 33 (IL-33), which is a potent inducer of type 2 immune response, has been confirmed to be involved in the development and progression of multiple fibrotic diseases. However, the role and mechanism of IL-33 in SSc-related fibrosis remains unclear.

Objectives: To clarify the role of interleukin 33 (IL-33) and its receptor Suppression of tumorigenicity 2 (ST2) in the skin fibrosis of SSc, so to provides a new target for the treatment of fibrosis in patients with SSc.

Methods: The levels of IL-33 and ST2 was analysed in human samples, murine models of SSc and in cultured fibroblasts by immunohistochemistry and immu nofluorescence. The functional role of IL-33 was evaluated by detecting changes 